\title{
Short QT Syndrome
}

National Cancer Institute

\section{Source}

National Cancer Institute. Short QT Syndrome. NCI Thesaurus. Code C71060.

Ventricular tachyarrhythmias occurring in association with short QT syndrome. 